Check for updates

Cite this: RSC Adv., 2019, 9, 4693

Received 17th October 2018 Accepted 13th January 2019

DOI: $10.1039 / c 8 r a 08604 d$

rsc.li/rsc-advances

\section{Facile synthesis of a $\mathrm{Bi}_{2} \mathrm{MoO}_{6} / \mathrm{TiO}_{2}$ nanotube arrays composite by the solvothermal method and its application for high-performance supercapacitor}

\author{
Jiang Wen, Shupei Sun, Bo Zhang, Nianfeng Shi, Xiaoming Liao, (D) * Guangfu Yin, \\ Zhongbing Huang, (D) Xianchun Chen and Ximing Pu
}

In this study, bismuth molybdate/titania nanotube arrays $\left(\mathrm{Bi}_{2} \mathrm{MoO}_{6} / \mathrm{TNTs}\right)$ as a binder-free electrode for supercapacitors were fabricated via a facile solvothermal method. The effects of precursor amounts, solvothermal time and temperature on the microstructure and electrochemical properties of the composite were analyzed. The surface morphology, microstructure, chemical composition and chemical states of the composite electrode material were analyzed using scanning electron microscopy, $X$-ray diffraction, energy dispersive $\mathrm{X}$-ray spectroscopy, and $\mathrm{X}$-ray photoelectron spectroscopy. Cyclic voltammetry tests, galvanostatic charge-discharge measurements, and electrochemical impedance spectroscopy were employed to analyze the electrochemical behavior of the composite. A specific capacitance of $\sim 330 \mathrm{mF} \mathrm{cm}{ }^{-2}$ has been achieved for this $\mathrm{Bi}_{2} \mathrm{MoO}_{6}$ nanosheets/TNTs composite electrode at the current density of $1 \mathrm{~mA} \mathrm{~cm}{ }^{-2}$. Galvanostatic charge-discharge experiments suggest a moderate cycling stability together with $76.7 \%$ capacitance retention after 1000 cycles of continuous charge-discharge operation. These results indicate that the $\mathrm{Bi}_{2} \mathrm{MoO}_{6} / \mathrm{TNT}$ composite is a promising electrode material for supercapacitors.

\section{Introduction}

The current global energy crisis and environmental issues have led to an urgent need to exploit sustainable energy storage/ conversion devices. ${ }^{1-3}$ As a momentous means of electrical energy storage through electrical double layer capacitance or pseudocapacitance, supercapacitors (SCs) have attracted tremendous attention, mainly due to their fast rechargeability, high power density, long cycle life, and bridging function for the energy and power gap between traditional dielectric capacitors and batteries. ${ }^{4-6}$ Carbon-active materials are generally employed as electrical double-layer capacitors (EDLCs), which adopt electrostatic charge diffusion and accumulation at the electrode/electrolyte interface as a charge storage mechanism..$^{7-9}$ In contrast, pseudocapacitors exhibit a much higher specific capacitance compared with EDLCs owing to the fast and reversible redox reactions at the surface or subsurface of the electrodes. Therefore, they have the potential to meet the higher requirements of future energy storage systems. ${ }^{\mathbf{1 0}}$ Nevertheless, some intrinsic drawbacks of the active materials used in SCs, such as poor electrical conductivity, ${ }^{\mathbf{1 1}}$ inferior electrochemical properties ${ }^{6,12,13}$ and a limited electrolyte-accessible

College of Materials Science and Engineering, Sichuan University, Chengdu, Sichuan 610065, China. E-mail: sherman_xm@163.com; Fax: +862885413003

$\dagger$ Electronic supplementary information (ESI) available. See DOI: 10.1039/c8ra08604d surface area $^{\mathbf{1 4 , 1 5}}$ still exist, which are vital barriers towards boosting specific capacitance.

Among various supercapacitor materials (e.g., carbon nanotubes, ${ }^{7} \mathrm{RuO}_{2},{ }^{16,17} \mathrm{MnO}_{2},{ }^{14,18} \mathrm{NiO}^{19,20}$ and polyaniline ${ }^{21}$ ), titanium dioxide nanotube arrays (TNTs) possess a highly ordered structure and large surface area, which promote charge and ion transfer as well as increase the reaction sites. ${ }^{22}$ However, the semiconducting nature and poor electrical conductivity of titanium dioxide $\left(\mathrm{TiO}_{2}\right)$ lead to lower electrochemical activity, and thus reduce its energy density. ${ }^{11,13}$ In addition to doping with other elements ${ }^{23}$ and thermal annealing, ${ }^{24}$ the synthesis of nanocomposites with other electroactive materials (e.g., transition metal oxides, binary metal oxides, and polymers) could greatly enhance the capacitance of TNTs. For example, Ramadoss et al. reported that the nanostructured $\mathrm{TiO}_{2} @ \mathrm{MnO}_{2}$ coreshell exhibited excellent electrochemical properties with an improved areal capacitance of $22.19 \mathrm{mF} \mathrm{cm}^{-2}$ at a scan rate of $5 \mathrm{mV} \mathrm{s}^{-1}$ in a $1 \mathrm{M} \mathrm{Na}_{2} \mathrm{SO}_{4}$ electrolyte solution. ${ }^{25}$ Sarkar et al. showed that the $\mathrm{TiO}_{2} / \mathrm{BiFeO}_{3}$ nanostructure yielded an enhanced capacitance of $440 \mathrm{~F} \mathrm{~g}^{-1}$ at a current density of $1.1 \mathrm{~A} \mathrm{~g}^{-1}$ in a $0.5 \mathrm{M} \mathrm{Na}_{2} \mathrm{SO}_{4}$ aqueous solution. ${ }^{26}$ The composite electrode can combine the large surface area of TNTs and the reversible electrochemical redox reaction of the electroactive materials, providing a better candidate for supercapacitors. ${ }^{25}$

Bismuth molybdate $\left(\mathrm{Bi}_{2} \mathrm{MoO}_{6}\right)$, a typical layered Aurivillius oxide consisting of $\left[\mathrm{Bi}_{2} \mathrm{O}_{2}\right]^{2+}$ layers sandwiched between $\left[\mathrm{MO}_{4}\right]^{2-}$ slabs, is widely used in photocatalytic applications due 
to its special physicochemical properties. ${ }^{27,28}$ Furthermore, $\mathrm{Bi}_{2} \mathrm{MoO}_{6}$ has also been studied in recent years as a good electrode material for supercapacitors which delivers high specific capacitances of $1075 \mathrm{~F} \mathrm{~g}^{-1}\left(6 \mathrm{M} \mathrm{KOH}, 0.1 \mathrm{~A} \mathrm{~g}^{-1}\right)$ and $43 \mathrm{~F} \mathrm{~g}^{-1}$ $\left(1 \mathrm{M} \mathrm{Na}_{2} \mathrm{SO}_{4}, 5 \mathrm{mV} \mathrm{s}^{-1}\right) .{ }^{29,30}$ Senthilkumar et al. reported that the active electrode material, which was obtained through coating a small piece of graphite sheet with a slurry consisting of asprepared $\mathrm{Bi}_{2} \mathrm{MoO}_{6}$ nanoplates, carbon black, polyvinylidene fluoride and $N$-methyl-2-pyrrolidinone, exhibited a specific capacitance of $519 \mathrm{~F} \mathrm{~g}^{-1}$ at $5 \mathrm{mV} \mathrm{s}^{-1}$ in $1 \mathrm{M} \mathrm{NaOH}$ electrolyte. ${ }^{29}$ However, this typical method of preparing electrodes can lead to the generation of electrical contact resistance between the current collector and the electrode material. Recent research studies have manifested that the direct growth of the nanostructures on conductive substrates has the merits of enlarged contact surface areas, good ability to mitigate large volume alterations, and abundant electroactive sites. ${ }^{31,32}$ As a current collector, the well-aligned TNTs vertically oriented from the surface of a Ti substrate do not need a polymer binder and conductive additives. ${ }^{3,34}$ Therefore, $\mathrm{Bi}_{2} \mathrm{MoO}_{6}$ directly synthesized on the TNTs can not only result in higher volumetric energy density, but also eliminate ohmic resistance to some extent.

Inspired by the research above, we fabricated anatase TNTs by anodization and subsequent thermal treatment. Then, through a simple solvothermal method of loading $\mathrm{Bi}_{2} \mathrm{MoO}_{6}$ onto the TNTs substrate, we successfully fabricated $\mathrm{Bi}_{2} \mathrm{MoO}_{6} /$ TNTs composite materials. The effects of the solvothermal conditions (precursor amounts, solvothermal reaction time and temperature) on the crystal structure, morphology, elemental composition, chemical states and electrochemical behavior of the $\mathrm{Bi}_{2} \mathrm{MoO}_{6}$ /TNTs were also investigated. Our results demonstrate that the $\mathrm{Bi}_{2} \mathrm{MoO}_{6} / \mathrm{TNT}$ composite is a promising electrode material.

\section{Experimental procedure}

\subsection{Materials}

Titanium sheet (TA2, purity $>99.6 \%$, thickness of $1 \mathrm{~mm}$ ) was purchased from LuoKe titanium Ltd. Ethylene glycerol $\left(\mathrm{C}_{2} \mathrm{H}_{6} \mathrm{O}_{2}\right.$, purity $>99.5 \%$ ), ammonium fluoride $\left(\mathrm{NH}_{4} \mathrm{~F}\right.$, purity $\left.>96 \%\right)$, bismuth nitrate pentahydrate $\left[\mathrm{Bi}\left(\mathrm{NO}_{3}\right)_{3} \cdot 5 \mathrm{H}_{2} \mathrm{O}\right.$ (purity $\left.\left.>99.0 \%\right)\right]$ and sodium molybdate dihydrate $\left[\mathrm{Na}_{2} \mathrm{MoO}_{4} \cdot 2 \mathrm{H}_{2} \mathrm{O}\right.$ (purity > 99.0\%)] were purchased from KeLong Chemical Ltd. Other chemical reagents used in these experiments were of analytical grade and used without further purification. All aqueous solutions were prepared using deionized water.

\subsection{In situ preparation of anodized TNTs}

The well-ordered TNTs were produced through a one-step anodization. Prior to anodization, the $\mathrm{Ti}$ sheet with the dimensions of $10 \times 10 \times 1 \mathrm{~mm}^{3}$ was degreased by acetone, ethanol and deionized water, sequentially, under ultrasonication for $20 \mathrm{~min}$. The electrolyte solution was prepared by dissolving $0.3 \mathrm{wt} \% \mathrm{NH}_{4} \mathrm{~F}$ into $24.0 \mathrm{~mL} \mathrm{H}_{2} \mathrm{O}$ and $376.0 \mathrm{~mL}$ ethylene glycol. Then, the degreased Ti sheet was anodized at
$60 \mathrm{~V}$ for $30 \mathrm{~min}$ at $25^{\circ} \mathrm{C}$. Finally, after being rinsed with distilled water and dried in air, the obtained TNTs were annealed at $450{ }^{\circ} \mathrm{C}$ for $2 \mathrm{~h}$ and then naturally cooled to room temperature for improved crystallinity.

\subsection{Fabrication of $\mathrm{Bi}_{2} \mathrm{MoO}_{6} / \mathrm{TNT}$ composite}

The $\mathrm{Bi}_{2} \mathrm{MoO}_{6} /$ TNTs composite was synthesized via a solvothermal method (Scheme 1). In a typical case, $1.0 \mathrm{mmol}$ of $\mathrm{Bi}\left(\mathrm{NO}_{3}\right)_{3} \cdot 5 \mathrm{H}_{2} \mathrm{O}$ and $0.5 \mathrm{mmol} \mathrm{Na} \mathrm{MoO}_{4} \cdot 2 \mathrm{H}_{2} \mathrm{O}$ were dissolved in $50 \mathrm{~mL}$ ethylene glycol under stirring for $2 \mathrm{~h}$. Then, the resulting solution was transferred into a $80 \mathrm{~mL}$ Teflon-lined autoclave to submerge the as-prepared TNTs. Next, the mixture was maintained at $160{ }^{\circ} \mathrm{C}$ for different times $(4,8,12$ and $16 \mathrm{~h})$ and then cooled down to room temperature. The obtained samples were thoroughly washed with deionized water to remove any ionic residuals and dried in an oven at $60{ }^{\circ} \mathrm{C}$ for $12 \mathrm{~h}$. The $\mathrm{Bi}_{2} \mathrm{MoO}_{6} /$ TNTs prepared at $160{ }^{\circ} \mathrm{C}$ for the various durations, namely, $4 \mathrm{~h}$, $8 \mathrm{~h}, 12 \mathrm{~h}$ and $16 \mathrm{~h}$ were referred to as BMO/TNT-1, BMO/TNT-2, BMO/TNT-3 and BMO/TNT-4, respectively. For comparison, $\mathrm{Bi}_{2} \mathrm{MoO}_{6}$ directly grown on Ti sheets at optimum solvothermal conditions was referred to as $\mathrm{Bi}_{2} \mathrm{MoO}_{6} / \mathrm{Ti}$.

\subsection{Material characterizations}

The surface morphology and crystal structure of the fabricated samples were investigated by scanning electron microscopy (SEM, Hitachi S4800, Japan) and X-ray diffraction (XRD, X'Pert ProMPD, Holland), respectively. The chemical composition of the prepared samples was characterized by an energy dispersive X-ray spectroscope (EDS, Oxford) attached to an SEM. An X-ray photoelectron spectroscope (XPS, Escalab 250Xi, USA) was employed to analyze the compositions and chemical states of the samples.

\subsection{Electrochemical measurements}

The electrochemical properties were tested on a CHI660E (Chenhua, China) electrochemical working station with a three

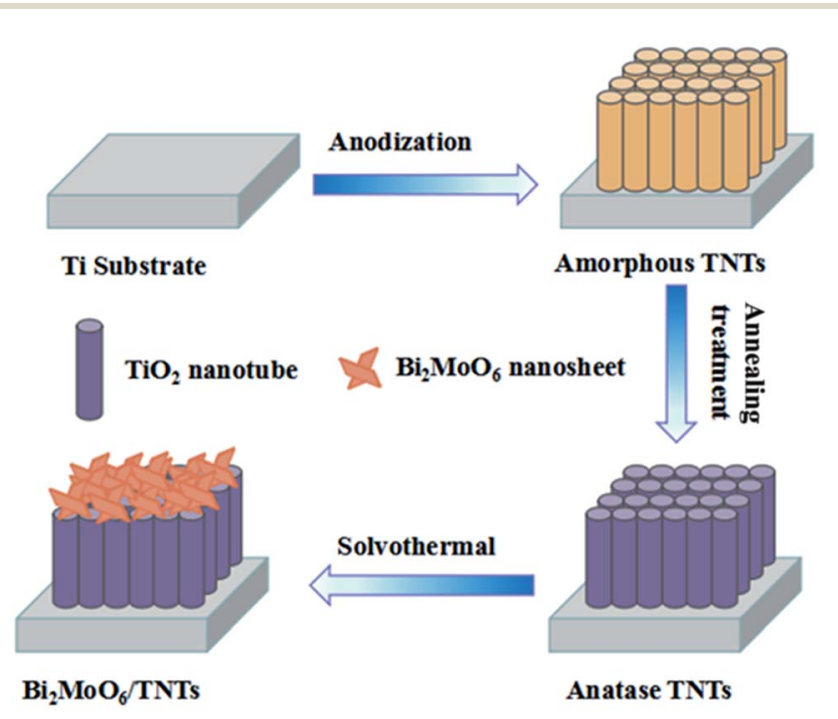

Scheme 1 Formation process of the $\mathrm{Bi}_{2} \mathrm{MoO}_{6} / \mathrm{TNT}$ composite. 
electrode system. The as-obtained $\mathrm{Bi}_{2} \mathrm{MoO}_{6} / \mathrm{TNT}$ and $\mathrm{Bi}_{2} \mathrm{MoO}_{6} /$ Ti were used as the working electrode. A platinum sheet and an $\mathrm{Ag} / \mathrm{AgCl}$ electrode were used as the counter and reference electrodes, respectively. All of the measurements were performed in $0.5 \mathrm{M} \mathrm{Na}_{2} \mathrm{SO}_{4}$ aqueous electrolyte solution at $25{ }^{\circ} \mathrm{C}$. The cyclic voltammetry (CV) measurements were performed in the potential range of -1.0 to $0 \mathrm{~V}$ at different scan rates of 10, 20, 40, 60,80 and $100 \mathrm{mV} \mathrm{s}^{-1}$. The galvanostatic charge-discharge (GCD) curves were performed by chronopotentiometry (CP) at different current densities of 1.0, 2.0, 3.0, 4.0 and $5.0 \mathrm{~mA} \mathrm{~cm}^{-2}$ in the above potential range. Electrochemical impedance spectroscopy (EIS) measurements were conducted over a frequency range of $0.01 \mathrm{~Hz}$ to $100 \mathrm{kHz}$ at an $\mathrm{AC}$ voltage amplitude of $5 \mathrm{mV}$. The cycling stability of the samples was tested by GCD measurements performed up to 1000 cycles at a current density of $1.0 \mathrm{~mA} \mathrm{~cm} \mathrm{~cm}^{-2}$.

\section{Results and discussion}

\subsection{Morphology and structure analyses}

In the forepart of this study, we found that the compositions and morphologies of the $\mathrm{Bi}_{2} \mathrm{MoO}_{6}$ /TNTs could be rationally tailored by simply adjusting the concentrations of both $\mathrm{Bi}\left(\mathrm{NO}_{3}\right)_{3} \cdot 5 \mathrm{H}_{2} \mathrm{O}$ and $\mathrm{Na}_{2} \mathrm{MoO}_{4} \cdot 2 \mathrm{H}_{2} \mathrm{O}$. The corresponding XRD patterns and SEM images are shown in Fig. S1.† The results indicate that the prepared sample presents a well-crystallized structure with uniformly distributed nanosheets when the content of $\mathrm{Na}_{2} \mathrm{MoO}_{4} \cdot 2 \mathrm{H}_{2} \mathrm{O}$ in the precursor is $0.5 \mathrm{mmol}$. In addition, the prepared sample also presents better electrochemical properties (Fig. S2 $\dagger$ ). Hence, $0.5 \mathrm{mmol}$ was chosen as the optimum concentration and the following samples were prepared at this concentration.

In addition to the precursor amounts, the reaction time also plays an important role in adjusting the morphologies of the $\mathrm{Bi}_{2} \mathrm{MoO}_{6} /$ TNTs. Fig. 1 shows the XRD patterns obtained over a $2 \theta$ range from $20^{\circ}$ to $80^{\circ}$ for TNTs, BMO/TNT-1, BMO/TNT-2,

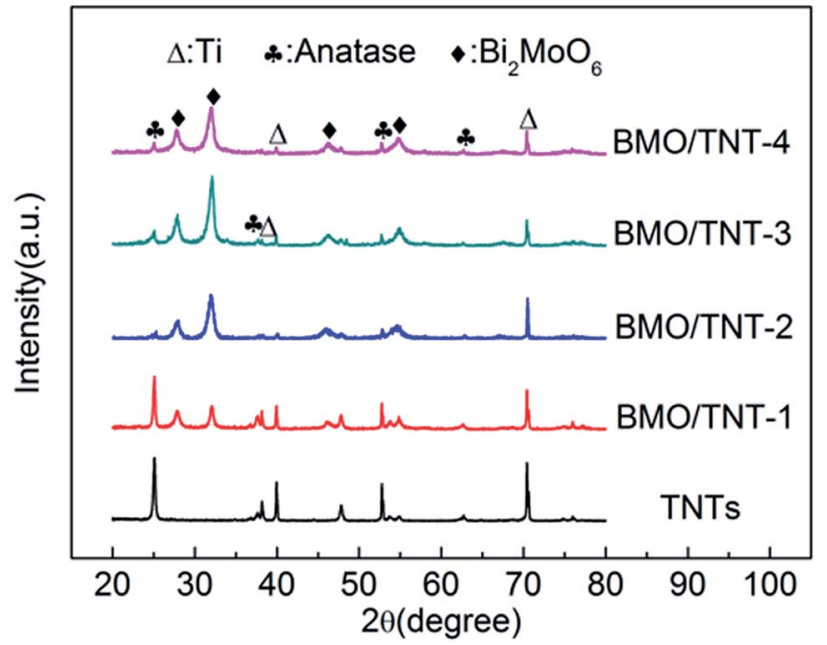

Fig. 1 XRD patterns of the TNTs, BMO/TNT-1, BMO/TNT-2, BMO/ TNT-3 and BMO/TNT-4 samples.
$\mathrm{BMO} / \mathrm{TNT}-3$ and $\mathrm{BMO} / \mathrm{TNT}-4$. It can be seen that the main diffraction peaks at $25.3^{\circ}, 37.9^{\circ}, 48.0^{\circ}$ and $53.9^{\circ}$ are perfectly indexed to the (101), (004), (200) and (105) planes of the anatase $\mathrm{TiO}_{2}$ phase, respectively (JCPDS no. 21-1272). The peaks at $38.3^{\circ}, 40.1^{\circ}$ and $70.7^{\circ}$ are assigned to the (002), (101), and (103) planes of the $\mathrm{Ti}$, respectively (JCPDS no. 44-1294). ${ }^{34}$ In the pattern of the $\mathrm{Bi}_{2} \mathrm{MoO}_{6} /$ TNTs, four distinct peaks with $2 \theta$ values of $28.3^{\circ}, 32.9^{\circ}, 47.1^{\circ}$ and $55.3^{\circ}$ can be well attributed to the (131), (200), (062) and (331) planes of the pure orthorhombic phase of $\mathrm{Bi}_{2} \mathrm{MoO}_{6}$, respectively (JCPDS no. 76-2388), ${ }^{27}$ indicating that the composites are composed of $\mathrm{Ti}$, $\mathrm{TiO}_{2}$ and $\mathrm{Bi}_{2} \mathrm{MoO}_{6}$. Furthermore, the influence of the solvothermal reaction time on the crystalline phase is also demonstrated through the changes in the XRD patterns. With the increase in the solvothermal time from $4 \mathrm{~h}$ to $12 \mathrm{~h}$, the diffraction peak intensity of $\mathrm{Bi}_{2} \mathrm{MoO}_{6}$ increases gradually. The XRD pattern of the $\mathrm{BMO} /$ TNT-3 shows higher intensity and narrower diffraction peaks than that of other samples, implying that the appropriate solvothermal reaction time can contribute to the enhancement of crystallization. ${ }^{28}$

Fig. 2 shows typical scanning electron microscopy (SEM) images of the as-prepared TNTs and $\mathrm{Bi}_{2} \mathrm{MoO}_{6} /$ TNTs. As shown in Fig. 2A and B, the obtained TNTs exhibit a highly arranged and uniform tubular structure with $\sim 80 \mathrm{~nm}$ pore diameter, $\sim 10 \mathrm{~nm}$ wall thickness and $\sim 1.7 \mu \mathrm{m}$ tube length. Fig. 3B-F show the SEM images of BMO/TNT-1, BMO/TNT-2, BMO/TNT-3 and $\mathrm{BMO} / \mathrm{TNT}-4$, from which significant differences in the morphologies of $\mathrm{Bi}_{2} \mathrm{MoO}_{6}$ can be observed. From Fig. 2C, we can see that the surface of the sample BMO/TNT-4 is covered with many small nanoslices, indicating that $\mathrm{Bi}_{2} \mathrm{MoO}_{6}$ nanocrystals are formed and grown on the TNTs. The $\mathrm{Bi}_{2} \mathrm{O}_{2}{ }^{2+}$ and
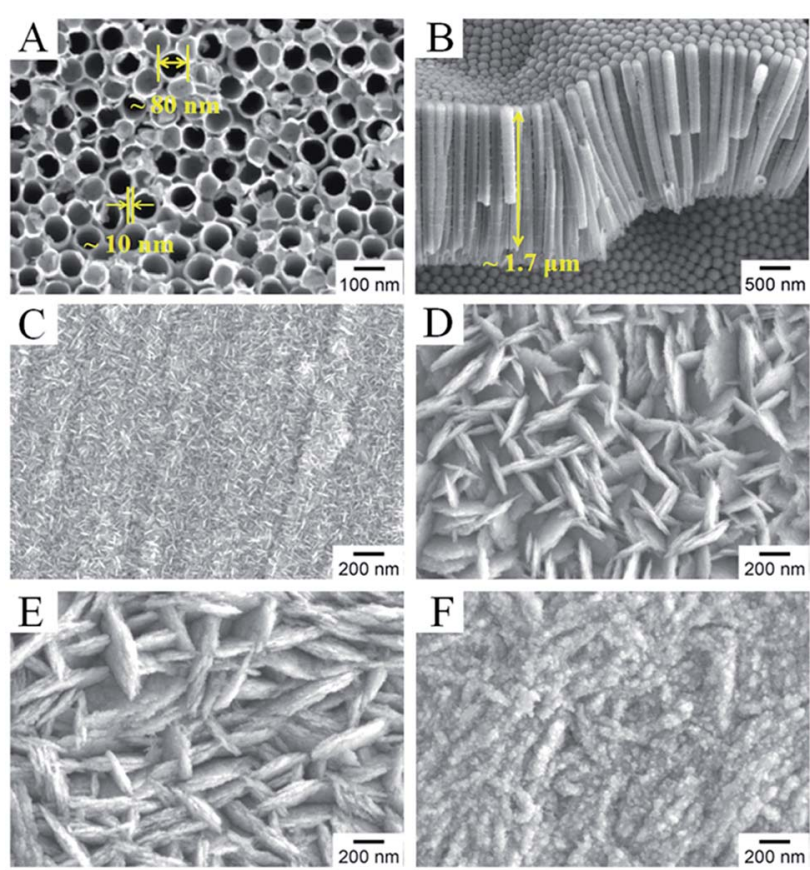

Fig. 2 SEM images of TNTs (A and B), BMO/TNT-1 (C), BMO/TNT-2 (D), BMO/TNT-3 (E) and BMO/TNT-4 (F). 

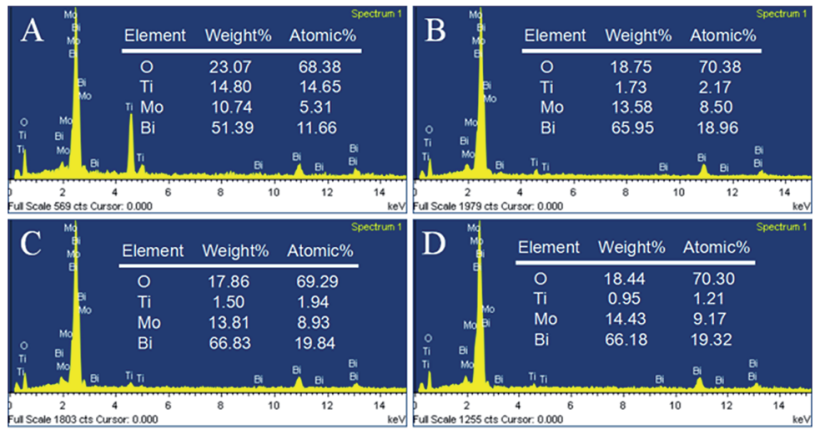

Fig. 3 EDS spectra of the BMO/TNT-1 (A), BMO/TNT-2 (B), BMO/ TNT-3 (C) and BMO/TNT-4 (D) samples.

$\mathrm{MoO}_{4}{ }^{2-}$ ions are generated under solvothermal conditions and further react to generate small nanoslices because of the high intrinsic anisotropic properties of $\mathrm{Bi}_{2} \mathrm{MoO}_{6} \cdot{ }^{35}$ With the reaction continuing for $8 \mathrm{~h}$, these small nanoslices gradually grow and further change into two-dimensional flake-like structures, predominantly with a length of 200-250 nm. As shown in Fig. $2 \mathrm{E}$, the nanosheets with a larger size are obtained after $12 \mathrm{~h}$. With the solvothermal reaction time prolonging to $16 \mathrm{~h}$, a significant change in morphology occurs and the surface of the TNTs is uniformly composed of granule-shaped agglomerates, which apparently develop from the nanosheets. Fig. 3 shows the EDS spectra of the BMO/TNT-1, BMO/TNT-2, BMO/ TNT-3 and BMO/TNT-4 composites. The result confirms that the $\mathrm{Bi}_{2} \mathrm{MoO}_{6} / \mathrm{TNT}$ composites are composed of $\mathrm{Ti}, \mathrm{Bi}$, Mo, and $\mathrm{O}$ elements. In addition, the atomic ratios of $\mathrm{Bi}$ to $\mathrm{Ti}$ increase from $0.80: 1$ to $8.74: 1,10.22: 1$, and $15.97: 1$ when the solvothermal reaction time is increased from 4 to 8,12 , and $16 \mathrm{~h}$, respectively. The EDS measurements verify that the amounts of the $\mathrm{Bi}_{2} \mathrm{MoO}_{6}$ nanosheets deposited on the TNTs increase with the increase in the reaction time.

To further understand the elemental composition and chemical states of the as-prepared BMO/TNT-3 nanocomposite,
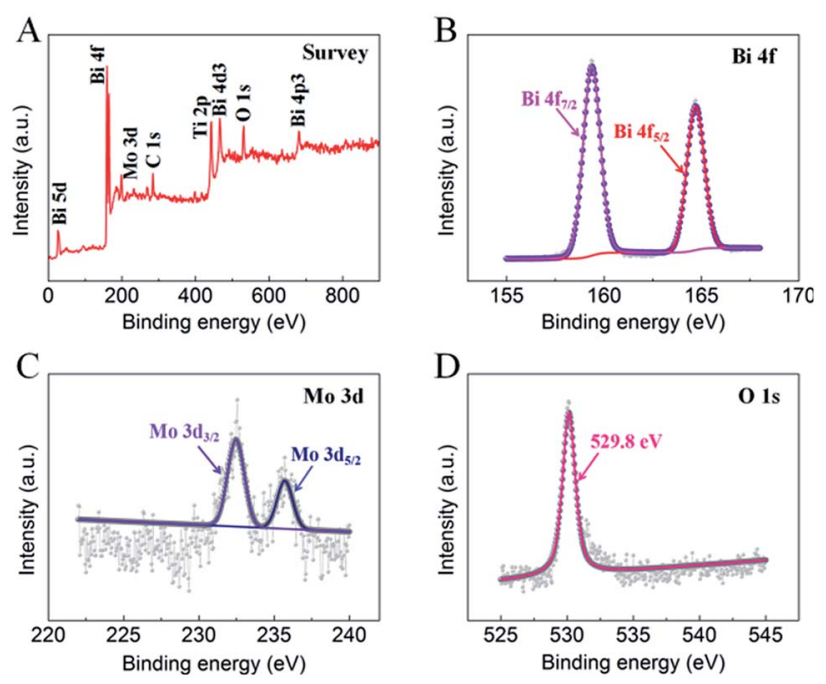

Fig. 4 XPS spectra of the as-prepared BMO/TNT-3 nanocomposite: survey (A), Bi 4f (B), Mo 3d (C) and O 1s (D).
XPS measurements were performed and the results are shown in Fig. 4. The peaks appearing at $284.5 \mathrm{eV}, 532.4 \mathrm{eV}$ and $458.9 \mathrm{eV}$ refer to $\mathrm{C} 1 \mathrm{~s}, \mathrm{O} 1 \mathrm{~s}$ and $\mathrm{Ti} 2 \mathrm{p}$, respectively (Fig. 4A). As shown in Fig. $4 \mathrm{~B}$, the two peaks are centered at $159.0 \mathrm{eV}$ for $\mathrm{Bi} 4 \mathrm{f}_{7 / 2}$ and $164.1 \mathrm{eV}$ for $\mathrm{Bi} 4 \mathrm{f}_{5 / 2}$ with a spin energy separation of $5.1 \mathrm{eV}$, which shows that the $\mathrm{Bi}^{3+}$ oxidation state exists in the nanocomposite. $^{36}$ The Mo 3d core level spectrum (Fig. 4C) shows two peaks with binding energies of $232.1 \mathrm{eV}$ and $235.3 \mathrm{eV}$, corresponding to Mo $3 \mathrm{~d}_{5 / 2}$ and Mo $3 \mathrm{~d}_{3 / 2}$ of $\mathrm{Mo}^{6+}$, respectively. ${ }^{36}$ Therefore, these results indicate that the BMO/TNT-3 nanocomposite has been fabricated successfully, and are consistent with the XRD analysis.

\subsection{Electrochemical characterizations}

The cyclic voltammogram (CV) curves and galvanostatic chargedischarge (GCD) curves were investigated in a $0.5 \mathrm{M} \mathrm{Na}_{2} \mathrm{SO}_{4}$ aqueous electrolyte to evaluate the electrochemical properties of the prepared composites. The CV curves for the as-prepared samples collected at a scan rate of $40 \mathrm{mV} \mathrm{s}^{-1}$ are shown in Fig. 5A. In general, the CV curves show the occurrence of redox peaks, namely, an anodic peak at approximately $-0.7 \mathrm{~V}$ and a cathodic peak at approximately $-0.4 \mathrm{~V}$, indicating the existence of pseudocapacitive behavior. Moreover, this reaction resembled the redox properties of bismuth oxide resulting from faradaic reactions that occurred between $\mathrm{Bi}(\mathrm{III})$ and $\mathrm{Bi}$ metal. ${ }^{33}$ Compared with pristine $\mathrm{TiO}_{2} \mathrm{NTs}$, the increased current of the $\mathrm{CV}$ curves for the $\mathrm{Bi}_{2} \mathrm{MoO}_{6} / \mathrm{TNTs}$ composite clearly demonstrates improved electrochemical behavior. These results suggest that the introduction of $\mathrm{Bi}_{2} \mathrm{MoO}_{6}$ over the TNTs' surface significantly increases the active area of the reaction platform on the surface or near surface-based redox reactions and thus, the capacitive performance is enhanced. ${ }^{37}$
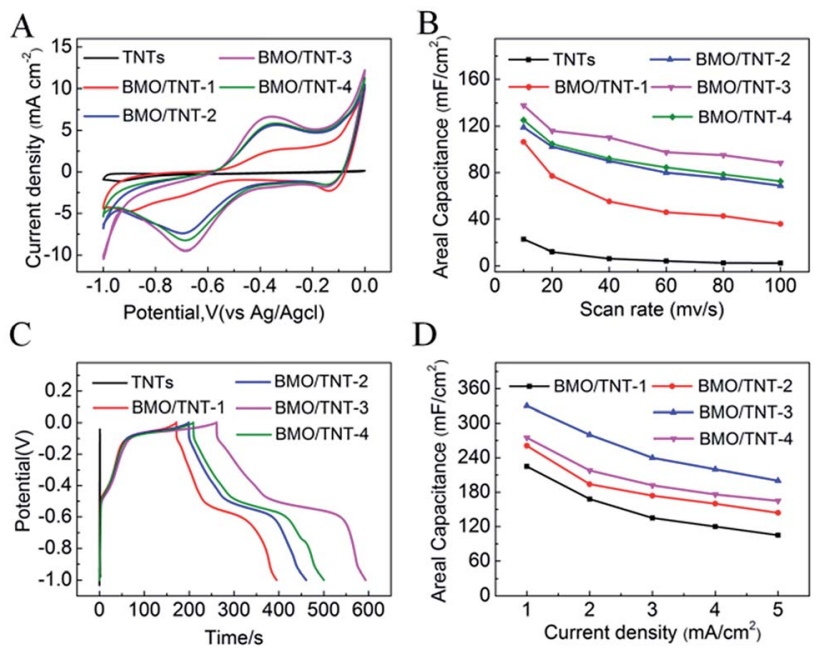

Fig. 5 The $\mathrm{CV}$ plots at a scan rate of $40 \mathrm{mV} \mathrm{s}^{-1}$ for TNTs, BMO/TNT-1, BMO/TNT-2, BMO/TNT-3 and BMO/TNT-4 (A), areal capacitances of the samples measured as a function of scan rate (B), the GCD curves at a current density of $1 \mathrm{~mA} \mathrm{~cm}{ }^{-2}$ for TNTs, BMO/TNT-1, BMO/TNT-2, $\mathrm{BMO} / \mathrm{TNT}-3$ and BMO/TNT-4 (C), the average areal capacitance at different current densities (D). 
On the basis of the integrated area under the CV curve, the specific capacitances can be calculated by the following equation:

$$
C_{\mathrm{s}}=C / S=I /[(\mathrm{d} V / \mathrm{d} t) \times S]
$$

The areal capacitances of the TNTs, BMO/TNT-1, BMO/TNT2, BMO/TNT-3 and BMO/TNT-4 are 6.3, 55.2, 90.1, 110.3 and $92.2 \mathrm{mF} \mathrm{cm}^{-2}$, respectively, at a scan rate of $40 \mathrm{mV} \mathrm{s}^{-1}$. The BMO/TNT-3 composited shows higher specific capacitance compared to $\mathrm{BMO} / \mathrm{TNT}-1$ and $\mathrm{BMO} / \mathrm{TNT}-2$. This is because BMO/TNT-3 has a better developed nanosheet structure and higher atomic ratio of $\mathrm{Bi}$ to $\mathrm{Ti}(15.97: 1)$, providing more active sites for faradaic reactions. We can see that the BMO/TNT-4 consists of the maximum amount of $\mathrm{Bi}_{2} \mathrm{MoO}_{6}$. However, the areal capacitance of BMO/TNT-4 is lower than that of BMO/TNT3. On one hand, it has been proved that the electrode material with excess density of active substances is unfavorable for the penetration of electrolytes. ${ }^{38}$ On the other hand, the BMO/TNT-3 composite presents a uniformly distributed nanosheet morphology, which has bigger openings and channels that will in turn help to reduce the mass transfer resistance of the electrolyte through the oxide phase into the TNTs substrate beneath during the electrochemical tests (CV, GCD). Thus, BMO/TNT-3 shows better electrochemical capacitive performance.

Fig. 5B shows the calculated areal capacitance of these electrodes as a function of scan rate. A decreasing trend of areal capacitance is observed in the $\mathrm{Bi}_{2} \mathrm{MoO}_{6} / \mathrm{TNT}$ composite electrode with an increase in the scan rate from 10 to $100 \mathrm{mV} \mathrm{s}^{-1}$. The inner active sites in the oxide layer are not readily accessible by the electrolyte at higher scan rates due to diffusion limitations. ${ }^{26}$ The sustainable redox transition is not complete with an increase in scan rate of the potential, leading to a decrease in the specific capacitance. The $\mathrm{CV}$ curves recorded at different scan rates and the GCD curves of the BMO/TNT-3 composite are shown in Fig. S4. $\dagger$ The figure shows that the current response of the electrode increases with the increase in scan rate and the shapes of the cyclic voltammogram curves remain almost invariant throughout the whole range of scan rates. These results suggest that the composite electrode materials have good capacitative response and stability. Notably, the specific capacitance of the BMO/TNT-3 composite remains as high as $88.5 \mathrm{mF} \mathrm{cm}^{-2}$ at a high scan rate $\left(100 \mathrm{mV} \mathrm{s}^{-1}\right)$, demonstrating good rate capability and ion transportation performance. This is due to the low resistance of the BMO/TNT-3 composite, which is an important factor in determining the rate performance for supercapacitor electrode materials. ${ }^{39}$ The GCD curves for the asprepared $\mathrm{Bi}_{2} \mathrm{MoO}_{6} /$ TNTs composite electrodes collected at a current density of $1.0 \mathrm{~mA} \mathrm{~cm} \mathrm{~cm}^{-2}$ are shown in Fig. $5 \mathrm{C}$. The nonlinear characteristic of the discharge curve indicates that the electrochemical reaction occurs following the redox mechanism, which is concordant with the CV results.

From the discharging curves, the specific capacitances can be calculated using the following equation:

$$
C_{\mathrm{s}}=[I \times \Delta t] /[S \times \Delta V]
$$

where $I$ is the discharge current, $\Delta t$ is the discharge time, $S$ is the surface area, and $\Delta V$ is the potential window. The areal capacitances of the TNTs, BMO/TNT-1, BMO/TNT-2, BMO/TNT3 and BMO/TNT-4 were 5.8, 225, 261, 330 and $275 \mathrm{mF} \mathrm{cm} \mathrm{cm}^{-2}$, respectively, at a current density of $1 \mathrm{~mA} \mathrm{~cm}^{-2}$. The BMO/TNT-3 sample possesses longer discharge time and higher specific capacitance than the other samples. Fig. 5D shows the trends of the areal capacitance as the current density increases from 1.0 to $5.0 \mathrm{~mA} \mathrm{~cm}{ }^{-2}$. It can be observed that the areal capacitance decreases with an increase in charge-discharge current density. At low current densities, the inner active sites or the pores of the electrode can be fully accessed and diffused with cations. Therefore, high areal capacitance values are obtained. This result is in agreement with the $\mathrm{CV}$ analysis (Fig. 5B). It is well indicated that the nanosheet structure is more favourable for fast electron transfer and electrolyte diffusion.

In this study, the effects of the solvothermal temperature on the structure and electrochemical behaviours of the $\mathrm{Bi}_{2} \mathrm{MoO}_{6} /$ TNTs composite were also investigated. The optimum solvothermal conditions $\left(1.0 \mathrm{mmol} \mathrm{Bi}\left(\mathrm{NO}_{3}\right)_{3} \cdot 5 \mathrm{H}_{2} \mathrm{O}\right.$ and $0.5 \mathrm{mmol}$ $\mathrm{Na}_{2} \mathrm{MoO}_{4} \cdot 2 \mathrm{H}_{2} \mathrm{O}$ dissolved in precursor, $160{ }^{\circ} \mathrm{C}, 12 \mathrm{~h}$ ) were determined (see ESI $\dagger$ ). To better illustrate the effect of TNTs on the morphological structure and electrochemical properties of the $\mathrm{Bi}_{2} \mathrm{MoO}_{6} / \mathrm{TNTs}$ composite, the sample with $\mathrm{Bi}_{2} \mathrm{MoO}_{6}$ nanosheets directly grown on a Ti plate at optimum solvothermal conditions was prepared and the corresponding capacitive behaviours were evaluated. As shown in Fig. S7, $\dagger$ the XRD pattern of the $\mathrm{Bi}_{2} \mathrm{MoO}_{6} / \mathrm{Ti}$ sample indicates that the composites are composed of a Ti and $\mathrm{Bi}_{2} \mathrm{MoO}_{6}$ phase. Fig. 6A shows the SEM images of $\mathrm{Bi}_{2} \mathrm{MoO}_{6} / \mathrm{Ti}$; a uniformly distributed thin nanosheet structure can be seen on the surface of the sample. Fig. 6B shows the EDS spectra of the $\mathrm{Bi}_{2} \mathrm{MoO}_{6} / \mathrm{Ti}$ composite. The atomic ratio of $\mathrm{Bi}$ to $\mathrm{Ti}(0.23: 1)$ is much less than that of $\mathrm{BMO} /$ TNT-3 (10.22: 1), indicating that the TNTs can provide more sites for the adsorption of metal ions $\left(\mathrm{Bi}^{3+}, \mathrm{Mo}^{6+}\right)$ as well as the nucleation and growth of $\mathrm{Bi}_{2} \mathrm{MoO}_{6}$ nanosheets. As shown in Fig. 6C, the areal capacitance of $\mathrm{Bi}_{2} \mathrm{MoO}_{6} / \mathrm{Ti}$ is $23.1 \mathrm{mF} \mathrm{cm}{ }^{-2}$ at
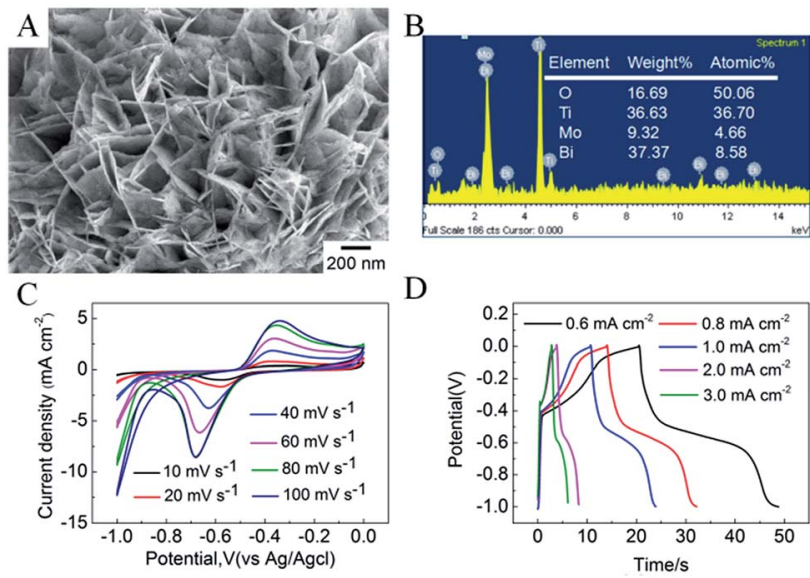

$\mathrm{D}$

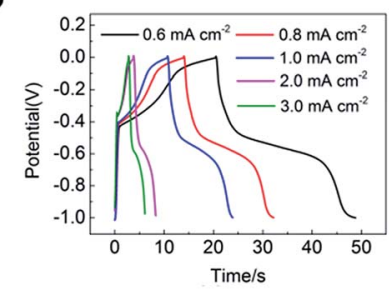

Fig. $6 \mathrm{SEM}$ images of $\mathrm{Bi}_{2} \mathrm{MoO}_{6} / \mathrm{Ti}(\mathrm{A})$, EDS spectrum of $\mathrm{Bi}_{2} \mathrm{MoO}_{6} / \mathrm{Ti}(\mathrm{B})$, the $\mathrm{CV}$ plots at different scan rates for $\mathrm{Bi}_{2} \mathrm{MoO}_{6} / \mathrm{Ti}(\mathrm{C})$, galvanostatic charge-discharge curves for $\mathrm{Bi}_{2} \mathrm{MoO}_{6} / \mathrm{Ti}$ (D). 
a scan rate of $40 \mathrm{mV} \mathrm{s}^{-1}$, which is also less than that of BMO/ TNT-3 (110.3 mF cm ${ }^{-2}$ ). Generally, compared with $\mathrm{Bi}_{2} \mathrm{MoO}_{6} /$ Ti, BMO/TNT-3 shows a uniformly distributed thick nanosheet morphology and better electrochemical performance, indicating that the existence of TNTs is beneficial to the formation of $\mathrm{Bi}_{2} \mathrm{MoO}_{6}$ nanosheets and improves the electrochemical properties of $\mathrm{Bi}_{2} \mathrm{MoO}_{6} / \mathrm{TNTs}$ composites.

In order to reveal the origin of the electrochemical behaviors of the electrodes, electrochemical impedance spectra (EIS) measurements were recorded over a frequency range of $0.01 \mathrm{~Hz}$ to $100 \mathrm{kHz}$. The Nyquist plots are presented in Fig. 7A. The EIS spectra are almost similar, consisting of a semicircle in the high-frequency region, followed by a sloped line in the lowfrequency region, which can be simulated by an equivalent circuit (see the bottom-right inset in Fig. 7A). Table 1 lists the fitted values for the elements of TNT and BMO/TNT-3. The linear part in the low frequency region represents the diffusive resistance of the electrolyte and proton diffusion in active materials, which can be described as the equivalent series resistance $\left(Z_{\mathrm{w}}\right)$. The Nyquist plot is a vertical line for an ideal electrode material. ${ }^{40}$

It can be seen that the slope of the straight line of the BMO/ TNT-3 electrode is significantly steeper than that of the TNTs, indicating the better capacitive behavior. In the high frequency region, the real axis intercept represents the internal resistance $\left(R_{\mathrm{S}}\right)$, including the sum of the intrinsic resistance of the active material, contact resistance at the active material/current collector interface and the ionic resistance of the electrolyte. The semicircle corresponds to the charge transfer resistance $\left(R_{\mathrm{ct}}\right){ }^{41,42}$ As listed in Table 1 , the fitted values for $R_{\mathrm{s}}, R_{\mathrm{ct}}$ and $Z_{\mathrm{w}}$ of BMO/TNT-12 are all smaller than those of the TNTs. This is mainly due to the high electrical conductivity and nanosheet structure of $\mathrm{Bi}_{2} \mathrm{MoO}_{6}$, which is in agreement with the CV analysis. $C_{\mathrm{d}}$ and $C_{\mathrm{f}}$ are the double layer capacitance and the faradaic pseudo-capacitance, respectively. ${ }^{43}$ Compared with the TNTs, the fitted values for $C_{\mathrm{d}}$ and $C_{\mathrm{f}}$ of BMO/TNT-3 are greater, which is attributed to the fast redox reactions of the active materials. These results demonstrated that the BMO/TNT-3 composite electrode with enhanced electrochemical performance, which is benefited from the combined effects of fast ion diffusion and low electron-transfer resistance, was superior to the other samples according to the measurements discussed above with reference to Fig. 5 and 7 .
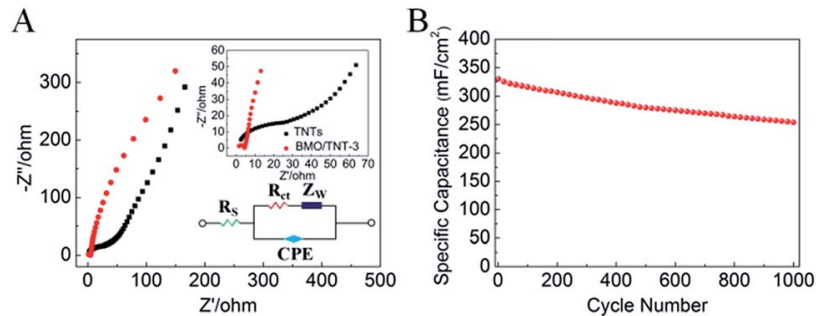

Fig. 7 (A) Nyquist plots of the TNTs and BMO/TNT-3 composite electrodes. The inset is an enlarged curve of the high frequency region and the equivalent circuit. (B) Cyclic performance of the BMO/TNT-3 composite electrodes at a current density of $1 \mathrm{~mA} \mathrm{~cm}^{-2}$.
Table 1 Equivalent circuit parameters for TNTs and BMO/TNT-3

\begin{tabular}{lll}
\hline & Fitting values & \\
\cline { 2 - 3 } $\begin{array}{l}\text { Equivalent circuit } \\
\text { elements }\end{array}$ & TNTs & BMO/TNT-3 \\
\hline$R_{\mathrm{s}}$ & 1.712 & 1.059 \\
$R_{\mathrm{ct}}$ & 14.08 & 3.34 \\
$W-\mathrm{R}$ & 98.5 & 0.88547 \\
$W-\mathrm{T}$ & 0.0033071 & 0.0033546 \\
$W-\mathrm{P}$ & 0.36687 & 0.45265 \\
$C_{\mathrm{d}}$ & $4.1727 \times 10^{-7}$ & $1.3009 \times 10^{-6}$ \\
$C_{\mathrm{f}}$ & 0.00081 & 0.0498
\end{tabular}

As shown in Fig. 7B, the BMO/TNT-3 composite exhibited $76.7 \%$ retention of the initial capacitance after 1000 cycles at 1 $\mathrm{mA} \mathrm{cm}^{-2}$, demonstrating the good cycling stability at high current densities. The decrease in active sites and the nanosheet structure damage caused by volume expansion during the cycling process are the main reasons for the reduction of the areal capacitance value. ${ }^{44}$ In spite of this, the areal capacitance value of BMO/TNT-3 still remained at $253 \mathrm{mF} \mathrm{cm}^{-2}$ after 1000 charge-discharge cycles.

\section{Conclusions}

In this study, we have reported a simple and optimized solvothermal method to synthesize a $\mathrm{Bi}_{2} \mathrm{MoO}_{6} / \mathrm{TNT}$ composite material for supercapacitor applications. The morphology of the $\mathrm{Bi}_{2} \mathrm{MoO}_{6}$ deposits is highly sensitive to the solvothermal parameters, specifically the precursor amounts, reaction time and reaction temperature. The results indicate that the areal capacitance of the composite materials can reach very high values $\left(\sim 330 \mathrm{mF} \mathrm{cm}^{-2}\right.$ at a current density of $\left.1 \mathrm{~mA} \mathrm{~cm}^{-2}\right)$, and the composites exhibit moderate cycling stability together with 76.7\% capacitance retention after 1000 continuous chargedischarge cycles. This high areal capacitance value is attained because of the combined effects of the redox reactions associated with the $\mathrm{Bi}_{2} \mathrm{MoO}_{6}$ in the presence of the electrolyte as well as the high surface area associated with the nanotubular nature of the substrate material. This study indicates that the $\mathrm{Bi}_{2} \mathrm{MoO}_{6} /$ TNTs composite electrode with enhanced capacitive performance holds potential for applications in storage devices.

\section{Conflicts of interest}

There are no conflicts to declare.

\section{Acknowledgements}

$\mathrm{J}$. Wen is very much grateful to Lingzhu Yu from the National Engineering Research Center for Biomaterials, Sichuan University for the assistance with the microscopy work. J. Wen thanks Ms Sun and Mr Luo for their care and support. 


\section{References}

1 Z. Q. Li, W. C. Chen, F. L. Guo, L. E. Mo, L. H. Hu and S. Y. Dai, Sci. Rep., 2015, 5, 14178-14185.

2 Z. N. Yu, L. Tetard, L. Zhai and J. Thomas, Energy Environ. Sci., 2015, 8, 702-730.

3 J. Yang, L. F. Lian, P. X. Xiong and M. D. Wei, Chem. Commun., 2014, 50, 5973-5975.

4 D. Guo, Y. Z. Luo, X. Z. Yu, Q. H. Li and T. H. Wang, Nano Energy, 2014, 8, 174-182.

5 X. H. Lu, M. H. Yu, G. M. Wang, Y. X. Tong and Y. Li, Energy Environ. Sci., 2014, 7, 2160-2181.

6 Y. Huang, M. S. Zhu, Y. Huang, H. F. Li, X. Pei, Q. Xue, Z. Liao, Z. F. Wang and C. Y. Zhi, J. Mater. Chem. A, 2016, 4, 4580-4586.

7 J. Xu, Z. Q. Tan, W. C. Zeng, G. X. Chen, S. L. Wu, Y. Zhao, K. Ni, Z. C. Tao, M. Ikram, H. X. Ji and Y. W. Zhu, Adv. Mater., 2016, 28, 5222-5228.

8 M. J. Zhi, C. C. Xiang, J. T. Li, M. Li and N. Q. Wu, Nanoscale, 2013, 5, 72-88.

9 S. Gao, K. Wang, Z. L. Du, Y. L. Wang, A. B. Yuan, W. Lu and L. W. Chen, Carbon, 2015, 92, 254-261.

10 J. Jiang, Y. Y. Li, J. P. Liu, X. T. Huang, C. Z. Yuan and X. W. Lou, Adv. Mater., 2012, 24, 5166-5180.

11 N. T. Nguyen, S. Ozkan, I. Hwang, X. M. Zhou and P. Schmuki, J. Mater. Chem. A, 2017, 5, 1895-1901.

12 L. X. Zheng, C. D. Wang, Y. C. Dong, H. D. Bian, T. F. Hung, J. Lu and Y. Y. Li, Appl. Surf. Sci., 2016, 362, 399-405.

13 H. M. Cui, Y. Chen, S. T. Lu, S. Y. Zhang, X. F. Zhu and Y. Song, Electrochim. Acta, 2017, 253, 455-462.

14 H. Xia, J. K. Feng, H. L. Wang, M. O. Lai and L. Lu, J. Power Sources, 2010, 195, 4410-4413.

15 D. Feng, Y. Y. Lv, Z. X. Wu, Y. Q. Dou, L. Han, Z. K. Sun, Y. G. Xia, G. F. Zheng and D. Y. Zhao, J. Am. Chem. Soc., 2011, 133, 15148-15156.

16 A. Ferris, S. Garbarino, D. Guay and D. Pech, Adv. Mater., 2015, 27, 6625-6629.

17 P. Chen, H. Chen, J. Qiu and C. W. Zhou, Nano Res., 2010, 3, 594-603.

18 X. H. Lu, D. Z. Zheng, T. Zhai, Z. Q. Liu, Y. Y. Huang, S. L. Xie and Y. X. Tong, Energy Environ. Sci., 2011, 4, 2915.

19 F. Gobal and M. Faraji, Electrochim. Acta, 2013, 100, 133-139. 20 Z. Gonzalez, B. Ferrari, A. J. Sanchez, A. Caballero and J. Morales, Electrochim. Acta, 2016, 211, 110-118.

21 D. S. Yuan, T. X. Zhou, S. L. Zhou, W. J. Zou, S. S. Mo and N. N. Xia, Electrochem. Commun., 2011, 13, 242-246.
22 B. Chen, J. Hou and K. Lu, Langmuir, 2013, 29, 5911-5919.

23 H. L. Tang, M. Xiong, D. Y. Qu, D. Liu, Z. J. Zhang, Z. Z. Xie, X. Wei, W. M. Tu and D. Y. Qu, Nano Energy, 2015, 15, 75-82. 24 M. Salari, K. Konstantinov and H. K. Liu, J. Mater. Chem., 2011, 21, 5128-5133.

25 A. Ramadoss and S. J. Kim, Int. J. Hydrogen Energy, 2014, 39, 12201-12212.

26 A. Sarkar, A. K. Singh, D. Sarkar, G. G. Khan and K. Mandal, ACS Sustainable Chem. Eng., 2015, 3, 2254-2263.

27 L. W. Zhang, T. G. Xu, X. Zhao and Y. F. Zhu, Appl. Catal., B, 2010, 98, 138-146.

28 G. H. Tian, Y. J. Chen, W. Zhou, K. Pan, Y. Z. Dong, C. G. Tian and H. G. Fu, J. Mater. Chem., 2011, 21, 887-892.

29 B. Senthilkumar, R. K. Selvan, L. Vasylechko and M. Minakshi, Solid State Sci., 2014, 35, 18-27.

30 Z. Q. Liu, L. Y. Tang, N. Li, K. Xiao, J. Wang, J. H. Zhang, Y. Z. Su and Y. X. Tong, J. Electrochem. Soc., 2012, 159, D582-D586.

31 H. D. Liu, J. L. Zhang, D. D. Xu, L. H. Huang, S. Z. Tan and W. J. Mai, J. Solid State Electrochem., 2015, 19, 135-144.

32 Z. P. Ma, G. J. Shao, Y. Q. Fan, G. L. Wang, J. J. Song and D. J. Shen, ACS Appl. Mater. Interfaces, 2016, 8, 9050-9058.

33 B. Sarma, A. L. Jurovitzki, Y. R. Smith, S. K. Mohanty and M. Misra, ACS Appl. Mater. Interfaces, 2013, 5, 1688-1697.

34 H. Zhou and Y. R. Zhang, J. Power Sources, 2014, 272, 866879.

35 L. S. Zhang, K. H. Wong, Z. G. Chen, J. C. Yu, J. C. Zhao, C. $\mathrm{Hu}$, C. Y. Chan and P. K. Wong, Appl. Catal., A, 2009, 363, 221-229.

36 F. S. Wu, X. H. Wang, W. R. Zheng, H. W. Gao, C. Hao and C. W. Ge, Electrochim. Acta, 2017, 245, 685-695.

37 A. K. Singh, D. Sarkar, G. G. Khan and K. Mandal, ACS Appl. Mater. Interfaces, 2014, 6, 4684-4692.

38 F. X. Bao, Z. Q. Zhang, W. Guo and X. Y. Liu, Electrochim. Acta, 2015, 157, 31-40.

39 R. B. Rakhi, W. Chen, D. Cha and H. N. Alshareef, J. Mater. Chem., 2011, 21, 16197-16204.

40 M. D. Stoller, S. Park, Y. W. Zhu, J. An and R. S. Ruoff, Nano Lett., 2008, 8, 3498-3502.

41 Z. J. Fan, J. Yan, T. Wei, L. J. Zhi, G. Q. Ning, T. Y. Li and F. Wei, Adv. Funct. Mater., 2011, 21, 2366-2375.

42 H. Peng, G. F. Ma, K. J. Sun, J. J. Mu, H. Wang and Z. Q. Lei, J. Mater. Chem. A, 2014, 2, 3303-3307.

43 M. Kundu and L. F. Liu, J. Power Sources, 2013, 243, 676-681. 44 Y. Ma, Y. L. Jia, L. N. Wang, M. Yang, Y. P. Bi and Y. X. Qi, J. Power Sources, 2016, 331, 481-486. 